Kaplan, H. S., and Rigler, L. G. (1945). Amer. J. med. Sci., 209 339.

L (1947). J. Lab. clin. Med., 32, 644.

Lawrence, J. C. (1936). Amer. J. Surg., 31, 499.

McRoberts, J. W. (1933). Proc. Mayo Clin., 8, 685.

Magnus, H. A., and Ungley, C. C. (1938). Lancet, 1, 420.

Miller, T. G., Eliason, E. L., and Wright, V. W. M. (1930). Arch. intern. Med.. 46, 841 .

Rigler, L. G., and Erickson, L. G. (1936). Radiology, 26, 6.

Stewart, M. J. (1929). British Medical Journal, 2, 567

Velde, G. (1938). Z. klin. Med., 134, 653.

Washburn. R. N., and Rozendaal, H. M. (1938). Ann. intern. Med. 11. 2172.

Wilkinson, J. F. (1949). Lancet, 1, 336.

\section{Atresia of the Small Intestine}

Congenital atresia of the intestine is not a common condition and it is rarely diagnosed at a stage when surgical treatment holds out a hope of success ; yet early diagnosis is relatively simple.

Vomiting always occurs on the first day of life and is persistent and increasing (Ladd and Gross, 1941). It almost invariably contains bile. These two findings distinguish the condition from hypertrophic pyloric stenosis. The stools are usually small, dry, and lighter in colour than normal meconium (Ladd and Gross, 1941 ; Potts, 1947). Absolute constipation is not the rule. Abdominal distension is variable, depending on the duration of the symptoms and the level of the lesion. When the atresia is in the ileum distension is usually marked and visible peristalsis is often present (Ladd and Gross, 1941 ; Potts, 1947). Dehydration is pronounced only if the condition has persisted for some days.

A plain radiograph of the abdomen, particularly if taken with the infant held erect, will not only establish the diagnosis of obstruction but will give a clue to its approximate level. The administration of barium in these cases is not only unnecessary but may be dangerous, as an inhalation of vomited barium may give rise to a fatal pneumonia.

Farber's test depends on the fact that normal meconium contains cornified epidermal cells from swallowed liquor amnii. If microscopical examination of a specimen of meconium (taken from the centre of a stool) shows absence of such cells complete obstruction of the intestine may be assumed. As stenosis is not excluded this test would seem to be of more academic than practical value. It should be stressed that repeated vomiting during the first 24 hours of life indicates the urgent need for radiographic investigation.

\section{CASE REPORT}

A baby girl, born at 4.30 p.m. on July 31, 1949 (weight, $6 \mathrm{lb} .12 \mathrm{oz} .-3.06 \mathrm{~kg}$.), was admitted to hospital at about $1 \mathrm{p.m}$. the next day with a diagnosis of imperforate anus and a history of repeated vomiting since birth and failure to pass meconium. - On examination the abdomen was distended. Ladder patterns and visible peristalsis were seen over the central and upper abdomen. Her clothes showed evidence of bile-stained vomit. Per rectum there was no difficulty in inserting a finger, and examination was followed at once by the passage of a normal looking tarry meconium. A radiograph of the abdomen (erect position) showed coils of distended small bowel with fluid levels. The radiologist (Dr. J. O. Y. Cole) reported "small-gut obstruction, probably mid-ileum."

A $10 \mathrm{E}$ rubber urethral catheter was passed into the stomach, and repeated aspirations were carried out. About $1 \mathrm{oz} .(28 \mathrm{ml}$. $)$ of bile-stained fluid was aspirated. Ringer-lactate solution, $100 \mathrm{ml}$., was injected subcutaneously.

Operation.-Anaesthesia was induced by ethyl chloride followed by nitrous oxide, oxygen, and ether (Dr. Reid).
A right paramedian incision centred opposite the umbilicus and $3 \mathrm{in.}(7.5 \mathrm{~cm}$.) in length was made. Grossly distended loops of small intestine presented and were allowed to prolapse freely. The distended bowel ended blindly about midileum, and at this point the gut was almost 2 in. $(5 \mathrm{~cm}$.) in diameter and very thin-walled, but not gangrenous. For the next 2 in. there was complete absence of intestine, the mesentery ending in a free edge just distal to the vascular arcades. The distal bowel was extremely small, the diameter being less than $\frac{1}{4}$ in. $(0.6 \mathrm{~cm}$.).

With a fine hypodermic needle some $30 \mathrm{ml}$. of air was injected into the distal loop, which promptly dilated to about $\frac{1}{2}$ in. $(1.25 \mathrm{~cm}$.) diameter and the pelvic colon could be felt distended with air. The proximal loop was aspirated and much gas and a little brown fluid were withdrawn, causing the loop to collapse considerably. The needle puncture was turned in with a purse-string suture of $3 / 0$ chromic catgut.

Using light clamps, a $1 \frac{1}{2}$-in. $(3.75-\mathrm{cm}$.) side-to-side anastomosis was made between the two loops by standard technique. As no suitable non-absorbable suture was available $3 / 0$ chromic catgut on an atraumatic needle was used for both layers. No tube was used and anastomosis was not difficult. The gap in the mesentery was closed and the bowel was returned to the abdomen. The abdomen was closed in layers, using $2 / 0$ chromic catgut for the deep layers and fine nylon for the skin.

The gastric catheter was left in place and aspirated houriy. Ringer-lactate solution, $100 \mathrm{ml}$., was injected subcutaneously at four-hourly intervals for 24 hours. Rectal salines, 4 oz. (114 ml.), were injected four-hourly, partly with a view to increasing fluid intake, but chiefly to distend the distal bowel. Penicillin, 50,000 units three-hourly, was given. The infant was nursed in an incubator with extra oxygen.

On August 2 only a few ounces of bile-stained fluid were aspirated. The bowels opened 12 hours after operationmeconium and a little blood. Next day, with the gastric tube in position, $1 \mathrm{oz}$. of $5 \%$ glucose was fed to the infant from a spoon at hourly intervals and aspirations were continued hourly (midway between feeds). After a few hours it was obvious that the fluid aspirated was much less than the intake. The bowels moved once again. Subcutaneous and rectal fluids were discontinued, the gastric tube was withdrawn, and glucose water was continued and gradually increased.

Three-hourly feeding with a reconstituted food was begun on August 4. From this point the feeding and care of the infant were left entirely to the nursing staff of the maternity unit and the baby was treated as "premature." The successful outcome of the case is due in no small measure to their devotion and skill. The child was discharged on September 17 and, apart from some fat intolerance, was normal. When seen on November 7 she was progressing normally and her weight was 11 lb. 4 oz. (5.1 kg.).

HARRY M. BENNETT, F.R.C.S.Ed.

REFERENCES

Ladd, W. E., and Gross, R. E. (1941). Abdominal Surgery of Infancy and Childhood. Philadelphia.

Potts, W. J. (1947). Surg. Gynec. Obstet., 85, 14.

In the not-too-distant future the number of pharmaceutical research scholarships may be substantially increased, Mr. C. W. Maplethorpe, chairman of the Pharmaceutical Society's education committee, stated in the course of an address on the society's education policy. There are already three such scholarships of the annual value of $£ 300$ each. A lease of a building, he added, had been taken for the establishment of a well-equipped laboratory for work in connexion with the scientific publications of the society. Because of the new opportunities in pharmacy, more young people were entering the profession. Since January they amounted to 784 , and if the number of entries during the remainder of the year was at the "same rate as last year they would exceed the entry figures for any year since 1933 . 